\title{
Wind Turbine Generator Short Circuit Fault Detection Using a Hybrid Approach of Wavelet Transform and Naïve Bayes Classifier
}

\author{
Hamid Toshani \\ School of Engineering \\ University of East Anglia (UEA) \\ Norwich, UK \\ H.Toshani@uea.ac.uk
}

\author{
Salman Abdi \\ School of Engineering \\ University of East Anglia (UEA) \\ Norwich, UK \\ S.Abdi-Jalebi@uea.ac.uk
}

\author{
Narges Khadem \\ Engineering Department \\ Iran University of Science and \\ Technology, Tehran, Iran \\ N_khadem@elec.iust.ac.ir
}

\author{
Ehsan Abdi \\ Wind Technologies Ltd \\ Cambridge, UK \\ Ehsan.Abdi@windtechnologies.com
}

\begin{abstract}
Wind turbines are subjected to several failure modes during their operation. A wind turbine drivetrain generally consists of rotor, bearings, low and high-speed shafts, gearbox, brakes, and generator. Single phase-to-phase and single phase-toground faults are among common electrical failure modes in the generator. In this paper, feature extraction has been performed using the Discrete Wavelet Transform (DWT) to detect the electrical faults in the wind turbine generator. A two-stage prediction process is proposed using Naïve Bayes Classifier (NBC), where the healthy and faulty modes are first determined, followed by classifying the types of electrical faults. Three-phase stator currents are used as fault detection signals. The performance of the proposed algorithm has been evaluated in Simulink for a $1659 \mathrm{~kW}$ wind turbine drivetrain.
\end{abstract}

Keywords-Wind Turbine Drivetrain, Fault Detection, Electrical Faults, Wavelet Transform, Nä̈ve Bayes Classifier

\section{INTRODUCTION}

Wind power generation is growing rapidly and the total installed capacity of wind turbines in both onshore and offshore sites has increased significantly during the last two decades from $7.5 \mathrm{GW}$ in 1997 to $651 \mathrm{GW}$ in 2019 [1]. The offshore wind is particularly expected to grow from $17 \mathrm{GW}$ in 2021 to $90 \mathrm{GW}$ in 2031 , taking about $15 \%$ of the global wind energy generation [2]. But the Levelised Cost of Energy (LCOE) still needs to be reduced in order to make offshore wind competitive with other means of conventional and renewable energy generation such as solar and nuclear energy.

A wind turbine drivetrain has several inter-connected electromechanical components such as generator, gearbox, bearings and power converter. Failure in these components can lead to a long downtime and hence high operation and maintenance costs for wind turbine operators, particularly in offshore installations where turbine accessibility is significantly restricted [3]. Consequently, real-time condition monitoring of wind turbines is of great interest to the operators to enable early detection of growing faults and hence to reduce the turbine downtime.

The performance of the generator can be affected by several failure modes including insulation damage, open-circuit fault, inter-turn short-circuit fault, phase-to-phase and phase-toground short-circuit faults, and electrical imbalance fault [3].
The current signature analysis has been proposed in the literature, for example by [4], in order to detect the inter-turn short-circuit fault in the stator winding. In this algorithm, the healthy and faulty mathematical models are defined and the Fast Fourier Transform (FFT) is used for frequency-domain analysis. However, no time-domain analysis is performed and the algorithm is valid only for a certain amount of short-circuit turns. A vector approach based on three-phase currents was proposed in [5] for detecting the open-circuit fault using the generator speed to define the detection threshold. This algorithm however has a slow fault detection rate which makes the fault classification challenging.

In order to detect the phase-to-ground fault, a method based on the likelihood function is proposed in [6], in which several data collection methods are used to collect the fault data. A probability distribution function is assigned for each method and the fault diagnosis is performed using the data fusion technique. The main issue with this technique is the possible conflicts between the results of different distribution functions.

A reliable fault detection technique can detect and classify faults with fast response, high accuracy and low complexity. In order to achieve this, the use of both time and frequency analyses is required. Discrete Wavelet Transform (DWT) is considered as a powerful analytical tool to extract the dynamic features of the drivetrain system including generator, gearbox, and bearings, since the monitoring data can be analysed with high resolution [7]. This algorithm is used in [8] to extract the harmonic components of the output power for obtaining the characteristics of generator faults. DWT is employed in [9] to detect the inter-turn short-circuit and resistive asymmetric faults in the stator winding. The inter-turn short-circuit fault causes a voltage unbalance in the stator winding. Hence, by sensing the voltage spectra for various shorted turns and applying them to the DWT algorithm, the fault can be detected. The proposed method is however not able to detect the faults for low levels of voltage unbalance according to [9]. The use of DWT in detecting open-circuit faults was reported in [10], where the features are obtained from the stator voltage signals and are used as inputs to a Neural Network (NN) to determine the type of fault. The NN performance was however shown to be degraded if rich data is not provided during the training process. 
Although the wavelet transform is a powerful method to identify various features of the measured fault signals, it is unable to perform fault classification. To detect and classify different faults, the extracted features obtained from DWT can be used to develop a predictive model capable of determining different types of faults. The Naive Bayes Classifier (NBC) is an effective approach to create fault classification models [11]. It uses several hypotheses based on the selected features and trains the predictive models by using the features as input data. Essentially, through using various fault data obtained from fault situations, the NBC technique trains the fault detection model to classify the faults [11]. An important strength of the NBC technique for wind drivetrain fault diagnosis is that it can be developed in a way to reliably detect faults at a wide range of wind speeds [12].

In this paper, mathematical and simulation models of a wind drivetrain are presented and described. The DWT and NBC methods are used to develop a complementary fault detection technique capable of both detecting and classifying two failure modes in the generator, namely phase-to-phase and phase-toground faults. The signals utilised for fault detection are the three-phase stator current signals. The wavelet functions are employed to determine the features in the fault detection signals such as skewness, kurtosis, mean, variance and orthogonal wavelets. Then, NBC is used to develop a predictive model capable of differentiating the healthy and faulty signals. The NBC technique is also employed to classify the two applied electrical faults. It is shown that the proposed hybrid approach is capable of both detecting faults and determining their types.

\section{WIND TURBINE MODEL USED IN SIMULATION}

The structure of the simulated wind turbine drivetrain including the generator and gearbox systems is shown in Fig. 1. The model was developed by MathWorks and reported in [13]. The rated power of the system is $1,659 \mathrm{~kW}$. The output of the generator is connected to the grid through a $1 \mathrm{Km}$ transmission line. The system has three modes of operation including startup, generating, and braking modes, where the desirable mode of operation is the generating mode.

In order to examine the practicality of the signal feature extraction, several wind speed profiles including constant and variable speeds with and without yaw control, are considered. A typical profile of the wind speed is shown in Fig. 2.

A two-stage planetary gearbox is considered in the simulation and its model is depicted in Fig. 3. For an ideal gearbox, the planet-sun gear ratio is:

$$
N=\frac{N_{r}}{N_{s}}
$$

where $N_{r}$ and $N_{s}$ are the number of teeth in the ring and the number of sun gear, respectively.

The generator model consists of an induction machine, rip breaker, transformer and several sensors as shown in Fig. 4. The induction machine is a squirrel-cage rotor type. The $d$ and $q$ axes electrical equations of the machine can be represented as:

$$
\begin{gathered}
V_{d s}=R_{s} i_{d s}+\frac{d \varphi_{d s}}{d t}-\Omega_{r f} \varphi_{q s} \\
V_{q r}^{\prime}=R_{r}^{\prime} i_{q r}^{\prime}+\frac{d \varphi_{q r}^{\prime}}{d t}+\left(\Omega_{r f}-\Omega_{e}\right) \varphi_{d r}^{\prime} \\
V_{d r}^{\prime}=R_{r}^{\prime} i_{d r}^{\prime}+\frac{d \varphi_{d r}^{\prime}}{d t}-\left(\Omega_{r f}-\Omega_{e}\right) \varphi_{q r}^{\prime} \\
T_{e}=1.5 p\left(\varphi_{d s} i_{q s}-\varphi_{q s} i_{d s}\right) \\
\varphi_{q s}=L_{s} i_{q s}+L_{m} i_{q r}^{\prime} \\
\varphi_{d s}=L_{s} i_{d s}+L_{m} i_{d r}^{\prime} \\
\varphi_{q r}^{\prime}=L_{r}^{\prime} i_{q r}^{\prime}+L_{m} i_{q s} \\
\varphi_{d r}^{\prime}=L_{r}^{\prime} i_{d r}^{\prime}+L_{m} i_{d s}
\end{gathered}
$$

where $R_{s}, L_{l s}, L_{m}, L_{s}, V_{q s}, i_{q s}, V_{d s}, i_{d s}, \varphi_{q s}, \varphi_{d s}$, and $p$ are the stator resistance, leakage inductance, magnetising inductance, total stator inductance, $q$ axis stator voltage and current, $d$ axis stator voltage and current, stator $q$ and $d$ axis fluxes, and number of pole pairs, respectively.

$\Omega_{r f}$ and $\Omega_{e}$ are the reference frame angular velocity and electrical angular velocity, respectively.

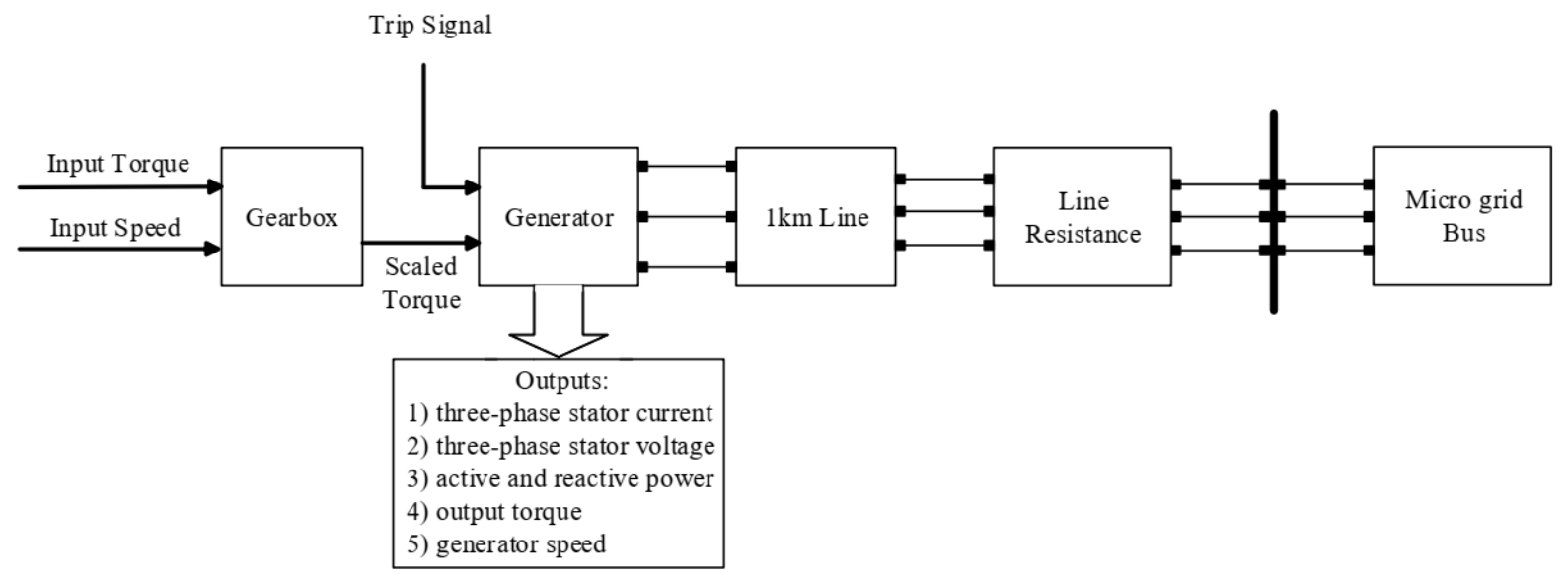

Fig. 1. The block diagram for the wind turbine drivetrain structure considered in the simulation. 


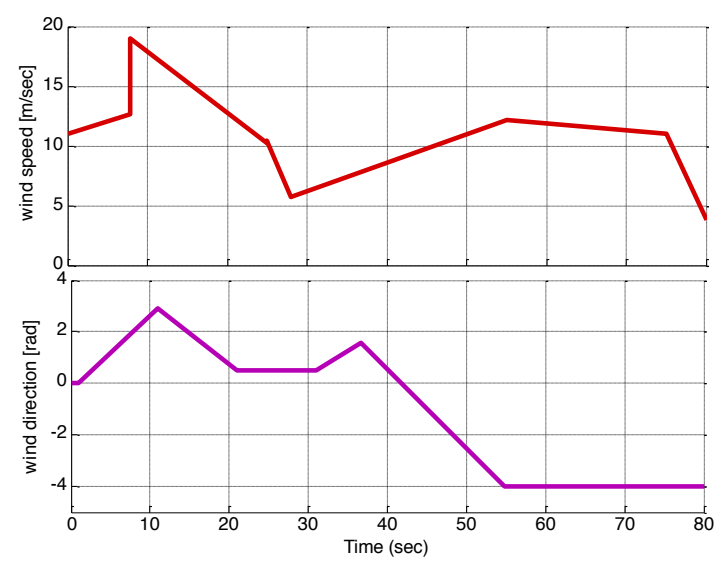

Fig. 2. An example of wind speed profile

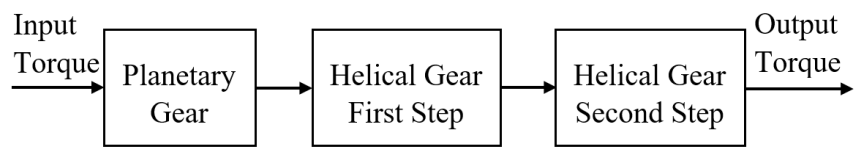

Fig. 3. The gearbox structure considered in drivetrain simulation.

The mechanical equations governing the drivetrain torque and speed can be represented as:

$$
\begin{aligned}
& \frac{d}{d t} \Omega_{r}=\frac{1}{2 H}\left(T_{e}-F \Omega_{r}-T_{m}\right) \\
& \frac{d}{d t} \theta_{r}=\Omega_{r}
\end{aligned}
$$

where $\theta_{r}, \Omega_{r}, T_{m}, T_{e}$ and $F$ are the rotor angular position and velocity, shaft mechanical torque, electromagnetic torque, and combined rotor and load viscous friction coefficient, respectively. The active power is obtained by three-phase voltage $v_{a b c}$ and current $i_{a b c}$ signals as follows:

$$
P=\frac{1}{2} \sum v_{a b c}^{T} \bar{i}_{a b c}
$$

In the generator simulation model shown in Fig. 4, single phase-to-phase and single phase-to-ground faults can be applied using the fault equivalent circuit model of the stator winding shown in Fig. 5. In this circuit, $R_{a}, R_{b}$, and $R_{c}$ are the stator winding resistances for phase $a, b$, and $c$, respectively, connected in star configuration. The phase-to-phase fault can be emulated by choosing $R_{a}$ and $R_{b}$ to be $0.001 \Omega$. The phase-toground fault can also be emulated when $R_{a}$ and $R_{g}$ are chosen to be $0.001 \Omega$.

\section{The Proposed FAult Detection ApproACH}

The proposed approach to detect the single phase-to-phase and single phase-to-ground faults in the generator is based on a hierarchical process, through which the fault feature extraction is performed using discrete wavelet transform (DWT), whereas the predictive models to classify the faults is fulfilled by the NBC method. Three-phase stator current signals are used to extract the fault features using the DWT algorithm. Fig. 6 shows the block diagram of the fault detection approach. As shown, the output data of the wind turbine drivetrain are applied to the feature extraction module. Then, the features are used to train the fault detection module. In this module, the healthy and faulty modes are distinguished at the first step, followed by the classification of different types of electrical faults in the second step.

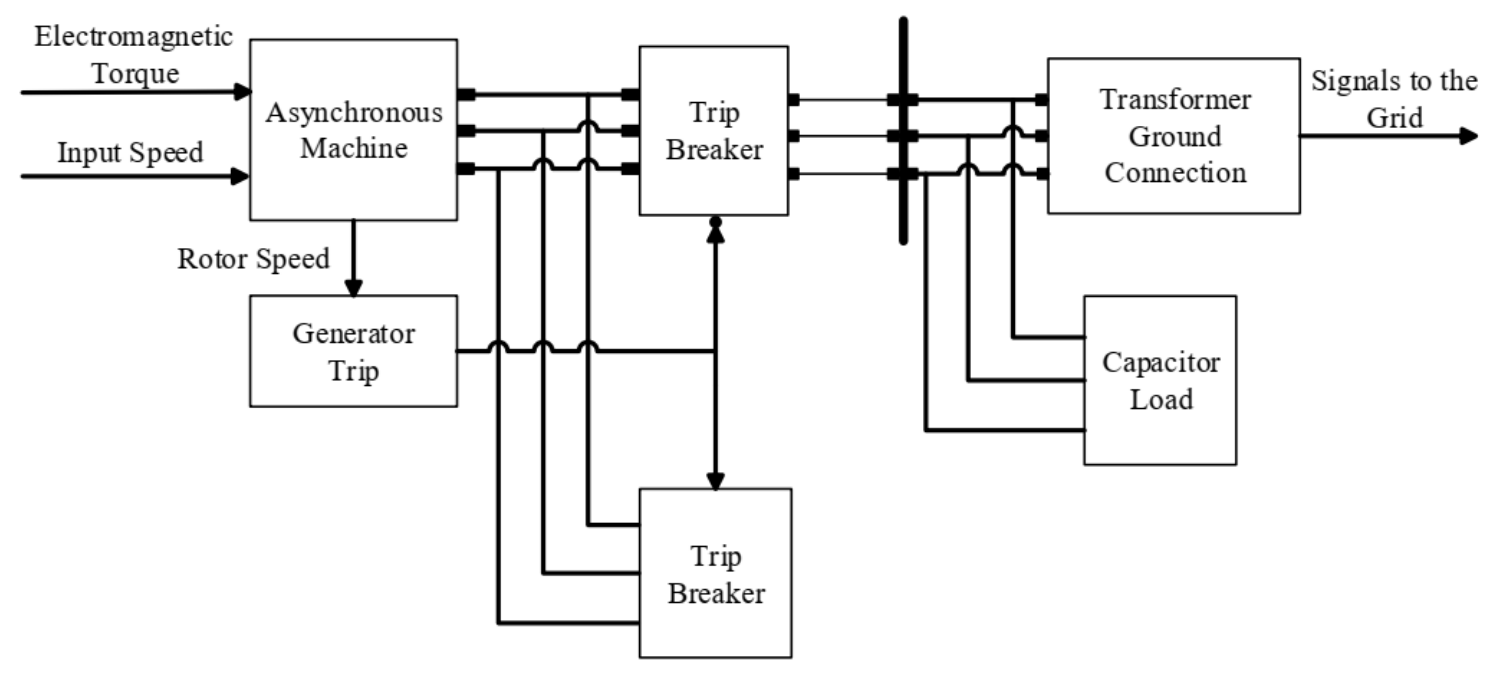

Fig. 4. The block diagram of the Induction generator considered in the simulation. 


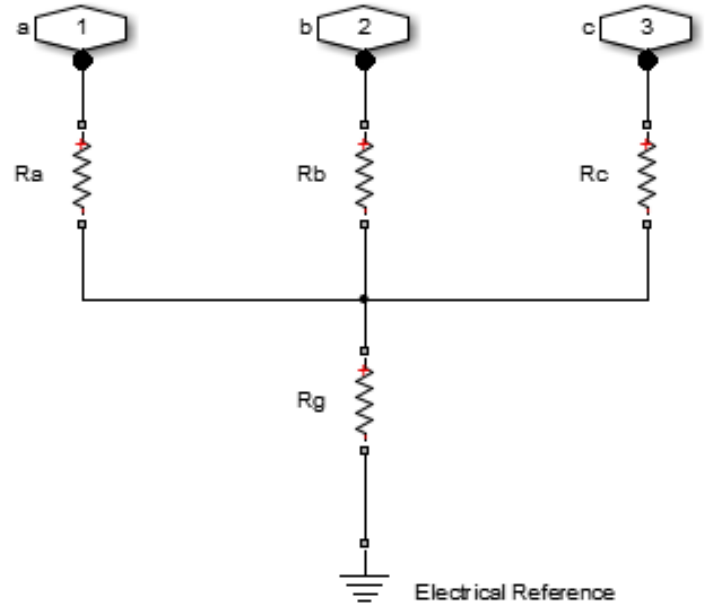

Fig. 5. The equivalent circuit model of the stator winding for short-circuit fault implementation.

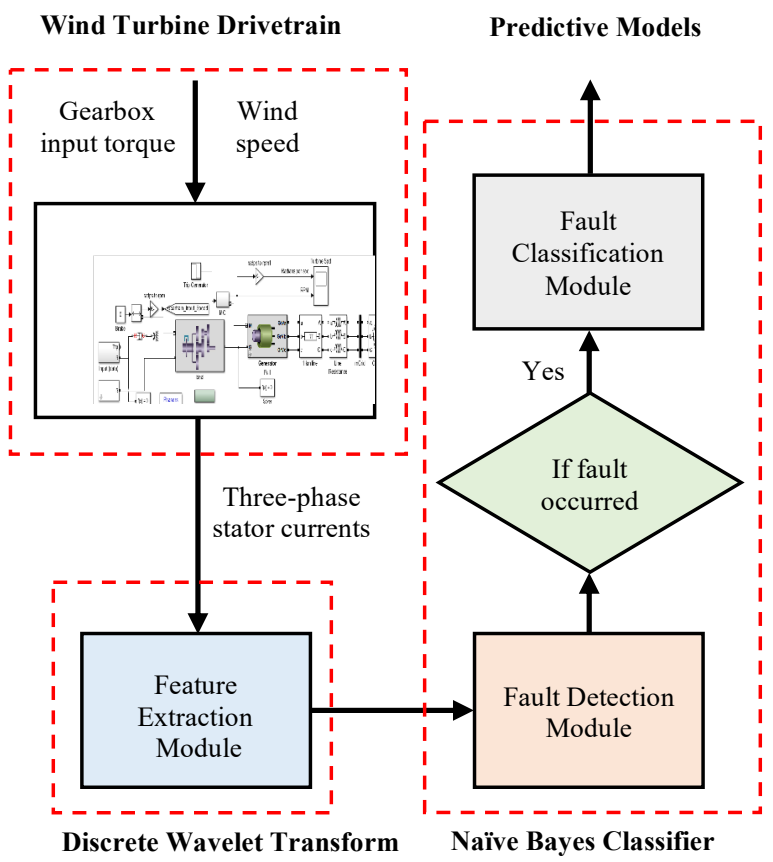

Fig. 6. The block diagram of the proposed hybrid fault detection approach

\section{A. Feature Extraction}

Consider $\beta(t)$ as a square integral function, its Fourier transform $\beta(w)$ holds for the following equation [14]:

$$
C_{w}=\int_{R} \frac{|\beta(w)|^{2}}{|w|} d w
$$

By defining $\beta(t)$ as mother wavelet function, several basis functions can be obtained through expanding and translating $\beta(t)$. A basis wavelet function is described as:

$$
\beta_{a, b}(t)=\frac{1}{\sqrt{a_{0}^{u}}} \beta\left(\frac{t-v a_{0}^{u} b_{0}}{a_{0}^{u}}\right), a_{0}, b_{0}, u, v \in Z, a_{0} \neq 0
$$

where $a_{0}$ and $b_{0}$ are the scale and translation parameters, respectively. Therefore, the DWT of $\beta(t)$ is defined as [14]:

$$
D W T_{\beta}(u, v)=\frac{1}{\sqrt{a_{0}^{u}}} \sum_{v} \beta(v) \beta\left(\frac{t-v a_{0}^{u} b_{0}}{a_{0}^{u}}\right)
$$

The considered features can be obtained using the wavelet transform expressed in (8).

\section{B. Naïve Bayes Classifier}

The Bayesian algorithm is a practical learning approach, in which explicit probabilities for some hypotheses are evaluated. Generally, for $k$ mutually exclusive and exhaustive classes $h_{i}, i=1,2, \ldots, k, P\left(D \mid h_{i}\right)$ denotes the probability of belonging D into class $h_{i}$. Hence, the posterior probability of class $h_{i}$ can be obtained [15]:

$$
P\left(h_{i} \mid D\right)=\frac{P\left(D \mid h_{i}\right) P\left(h_{i}\right)}{P(D)}=\frac{P\left(D \mid h_{i}\right) P\left(h_{i}\right)}{\sum_{i=1}^{k} P\left(D \mid h_{i}\right) P\left(h_{i}\right)}
$$

Among the set of generated hypotheses, it is vital to choose the best hypothesis. The NBC aims to simplify the hypotheses by considering the attributes which are conditionally independent of the target values. Essentially, the probability that the observation data $a_{1}, a_{2}, \ldots, a_{n}$ belong to the class $h_{i}$ is the product of the probabilities for the individual attributes:

$$
P\left(a_{1}, a_{2}, \ldots, a_{n} \mid h_{i}\right)=\arg \max _{h_{i}} \prod_{j} P\left(a_{i j} \mid h_{i}\right)
$$

Therefore, the resulted class of NBC can be obtained as

$$
h_{N B C}=\arg \max _{h_{i}} P\left(h_{i}\right) \prod_{j} P\left(a_{j} \mid h_{i}\right)
$$

The features derived using DWT are considered as the training data for the NBC algorithm. This technique leads to a predictive model to differentiate between the faulty and healthy signals using (9) and (10).

\section{Simulation Results}

The parameters of the wind turbine drivetrain are given in Table I. Based on a similar wind profile shown in Fig. 2, the threephase stator current signals have been obtained for both healthy and faulty conditions and shown in Fig. 7. The faults have been applied using the structure shown in Fig. 5.

It should be noted that to extract the features, the simulation model is run several times under healthy and faulty conditions, at various wind speed profiles. This is to improve the model accuracy in detecting and classifying faults at various wind profiles. The DWT decomposes a signal into levels with different time and frequency resolution. At each level, the approximation signals $A_{j}, j=1, \ldots, n$, represented by linear 
combinations of father wavelets, and detail signal $D_{j}, j=1, \ldots, n$, represented by linear combinations of mother wavelets can be generated. For a reference level $j$, the approximation of the main signal $S$ can be presented as follows:

$$
S=A_{j}+\sum_{j \leq J} D_{j}
$$

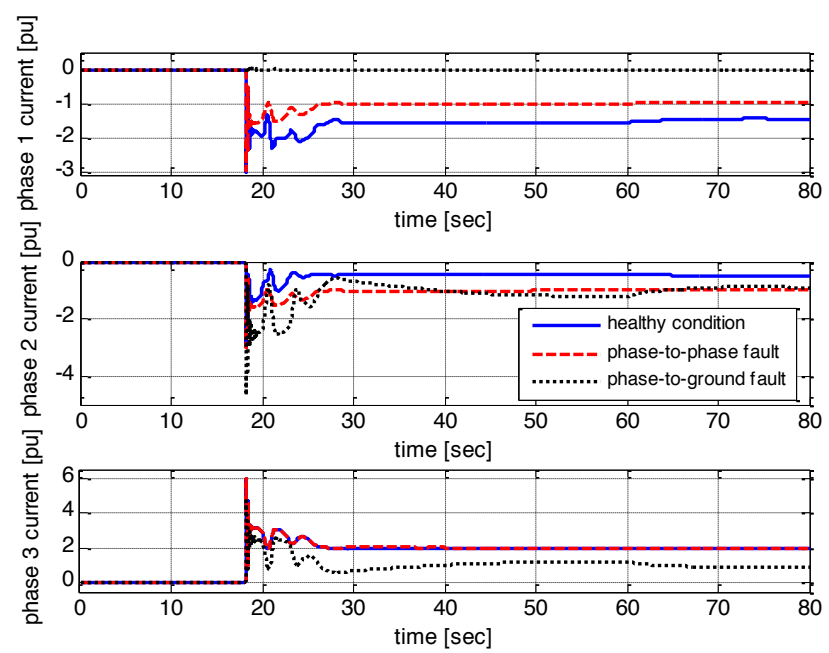

Fig. 7. The stator current signals at healthy and faulty conditions.

TABLE I. DRIVETRAIN PARAMETERS CONSIDERED IN THE SIMULATION

\begin{tabular}{cc}
\hline Aspect & Value \\
\hline Ratio & $1: 84.3$ \\
Mechanical power & $1800 \mathrm{~kW}$ \\
Rated power & $1650 \mathrm{~kW}$ \\
Rated current & $1740 \mathrm{~A}$ \\
No-load current & $430 \mathrm{~A}$ \\
Number of poles & 6 \\
Frequency & $60 \mathrm{~Hz}$ \\
Synchronous rotation speed & $1200 \mathrm{rpm}$ \\
Rotation speed at rated power & $1214 \mathrm{rpm}$
\end{tabular}

In this work, only detailed signals that show the significant disparities between healthy and faulty data are considered. As a result, the signals D4 to D7 are selected for both phase-to-phase and phase-to-ground faults. The results for phase-to-phase fault are shown in Fig. 8. The main features and their equations which are applied to the time-domain (three-phase stator currents), frequency-domain (Power Spectrum Density (PSD)), and timefrequency domain (D4-D7) signals are presented in Table II.

Based on Table II, the features are determined for the healthy and faulty signals, and their values are shown in Table III. As shown in Table III, for phase-to-phase fault, variance, the variance of power spectral density (PSD) for the fourth level of discrete wavelet decomposition (D4), and variance of D4 show differentiating values for fault conditions in comparison with the healthy condition. Furthermore, for phase-to-ground fault, skewness of the main signal, variance, mean, variance of PSD for $\mathrm{D} 4$, and kurtosis indicate clear discrepancies with healthy values. These feature values are used as input for NBC to train a predictive model for classifying the detected faults. In this paper, $70 \%$ of data is considered as training and the rest as test data.

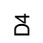
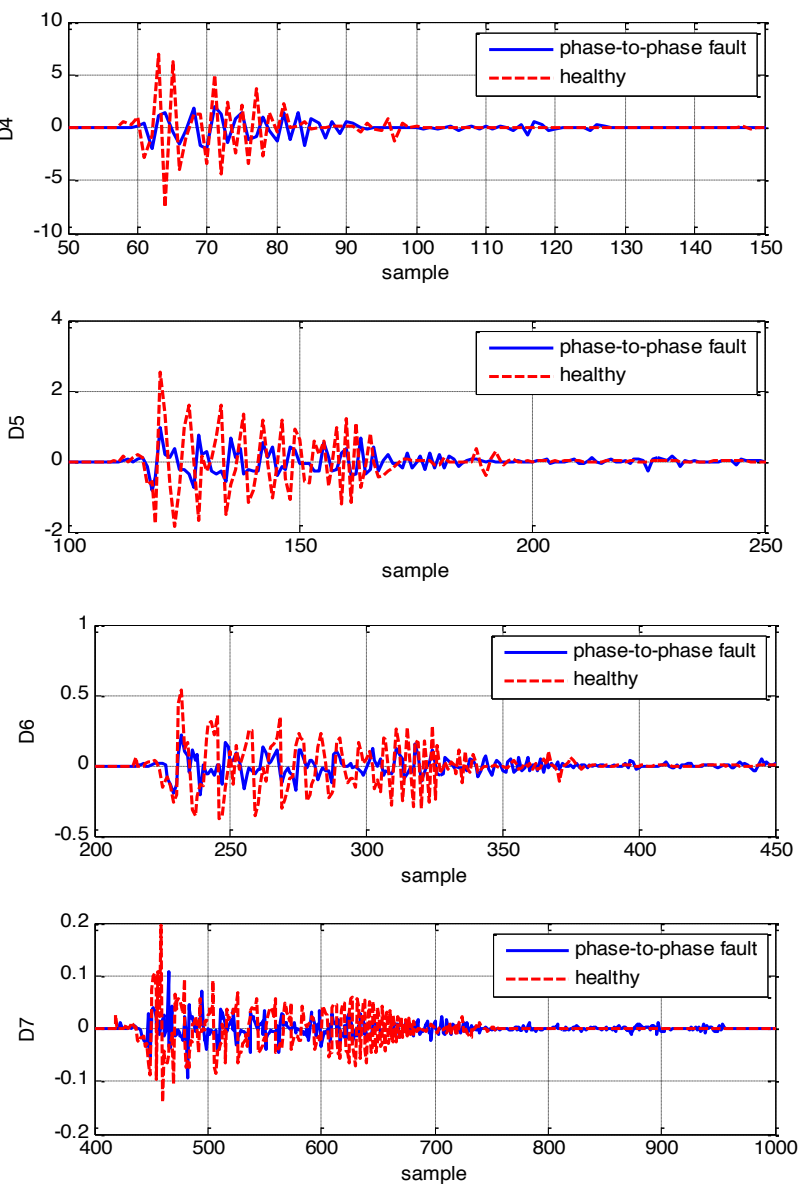

Fig. 8. The comparison of the D4-D7 wavelet signals for healthy condition and phase-to-phase fault condition.

TABLE II. THE MAIN FEATURES AND THEIR ASSOCIATED EQUATIONS

\begin{tabular}{|c|c|}
\hline Skewness & $x_{s k c}=\frac{\sum_{i=1}^{N}(x(i)-\bar{x})^{3}}{(N-1) x_{s t d}^{3}}$ \\
\hline Kurtosis & $x_{k u r}=\frac{\sum_{i=1}^{N}(x(i)-\bar{x})^{4}}{(N-1) x_{s t d}^{4}}$ \\
\hline Crest factor & $x_{c f}=\frac{x_{p}}{x_{r m s}}$ \\
\hline Mean & $\bar{x}=\frac{\sum_{i=1}^{N}|x(i)|}{N}$ \\
\hline Standard deviation & $x_{\text {std }}=\sqrt{\frac{\sum_{i=1}^{N}(x(i)-\bar{x})^{2}}{N}}$ \\
\hline
\end{tabular}


According to (10), the feature space including $a_{1}, a_{2}$ and $a_{n}$ is described using Gaussian distribution. NBC assigns data to the most probable class (healthy or faulty) and calculates densities of the features for each class. Classification is performed by estimating (9) and assigning the observation to the class yielding the maximum posterior probability. Moreover, $P\left(h_{i}\right)$ is the prior probability with class index $h_{i}$.

TABLE III. THE EXTRACTED FEATURE VALUES FOR HEALTHY AND FAULTY CONDITIONS OF THE GENERATOR

\begin{tabular}{c|cccccc}
\hline & Skewness & Variance & Mean & $\begin{array}{c}\text { D4 PSD } \\
\text { variance }\end{array}$ & $\begin{array}{c}\text { D4 } \\
\text { variance }\end{array}$ & Kurtosis \\
\hline Healthy & 0.3162 & 0.288 & 0.23 & 0.15 & 0.74 & 6.202 \\
\hline $\begin{array}{c}\text { Phase- } \\
\text { to-phase } \\
\text { fault }\end{array}$ & 0.3741 & 0.0734 & 0.107 & -0.23 & 0.12 & 6.3232 \\
\hline $\begin{array}{c}\text { Phase- } \\
\text { to- } \\
\text { ground } \\
\text { fault }\end{array}$ & -1.4170 & 0.0534 & 0.05 & 0.02 & 0.31 & 20.15 \\
\hline
\end{tabular}

To train the NBC algorithm, the healthy data are indicated with " +1 " and the faulty data with " -1 ". The performance is evaluated based on root mean square error (RMSE) for the test (RMSE_Test) and train (RMSE_Train) data, recall, and precision. By defining TP as a faulty signal that is correctly identified as fault, FP as a faulty signal incorrectly identified as healthy, and FN as a healthy signal incorrectly identified as fault, recall and precision can be described as follows [16]:

$$
\begin{aligned}
& \text { Precision }=\frac{T P}{T P+F P} \times 100 \\
& \text { Recall }=\frac{T P}{T P+F N} \times 100
\end{aligned}
$$

Table IV shows the evaluation results for the two different prior class probability distributions considered in this study i.e. $50 \%-50 \%$ and $70 \%-30 \%$. The main population of data $(50 \%$ or $70 \%$ in the above distributions) consist of healthy data and the remaining populations i.e. $50 \%$ or $30 \%$ are the fault data.

According to Table IV, the prior class probability distributions $50 \%-50 \%$ have more accuracy and less RMSE_Train and RMSE Test because its prior assumption is closer to its primary train data division.

TABLE IV. NBC RESULTS FOR GENERATOR SHORT CIRCUIT FAULT DETECTION

\begin{tabular}{cccccc}
\hline $\begin{array}{c}\text { Prior } \\
(\%)\end{array}$ & $\begin{array}{c}\text { Accuracy } \\
(\%)\end{array}$ & $\begin{array}{c}\text { Recall } \\
(\%)\end{array}$ & $\begin{array}{c}\text { Precision } \\
(\%)\end{array}$ & $\begin{array}{c}\text { RMSE_ } \\
\text { Test }\end{array}$ & RMSE_Train \\
\hline $50-50$ & 93.75 & 100 & 87.5 & 0.5 & 0.38 \\
\hline $70-30$ & 87.5 & 0.9 & 0.9 & 0.7 & 0.408 \\
\hline
\end{tabular}

Besides, a 10-fold cross-validation method is applied to evaluate how the results of the fault detection could be generalised to an independent data set. The Gaussian contours of faulty and healthy data for variance and skewness features are shown in Fig. 9. The contours denote the power density function of the 2-D Gaussian distributions, which are used to differentiate between the faulty and healthy data. It can be seen that most of the contours for healthy features do not overlap with the faulty feature contours showing the practicality of the NBC method in fault discrimination.

It is important to note that only the contours of variance and skewness features are used to verify the performance of the NBC classifier in this study. Other features such as mean and kurtosis may also be used from wavelet transform analysis as input data to the NBC technique.

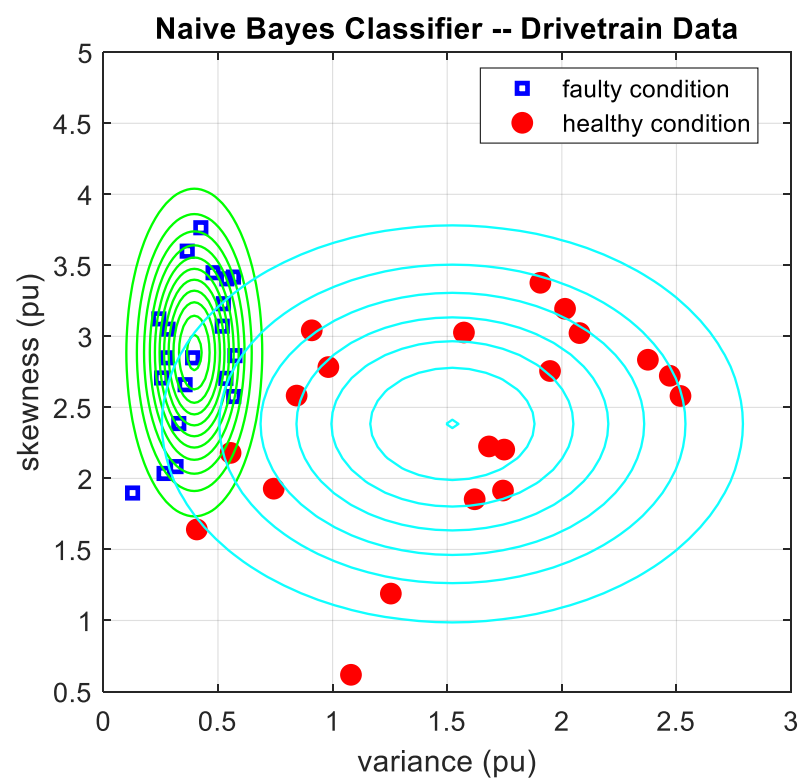

Fig. 9. The Gaussian contours of variance and skewness for faulty and healthy data using NBC classifier.

Table V shows the results for different percentages of train data. It can be seen that the accuracy of the classification is relatively acceptable for different sets of train data. The best performance can be achieved when $80 \%$ of the data is considered as the train data. In order to verify the NBC performance for fault classification, the results of the NBC classifier for variance and skewness features are shown in Fig. 10.

TABLE V. THE PERFormanCE INDEXES OF THE PROPOSED FAUlT Detection Algorithm AT DifFERENT PERCENTAGES OF TRAIN DATA

\begin{tabular}{cccccc}
\hline $\begin{array}{c}\text { Train } \\
\text { data } \\
(\%)\end{array}$ & $\begin{array}{c}\text { Accuracy } \\
(\%)\end{array}$ & $\begin{array}{c}\text { Recall } \\
(\%)\end{array}$ & $\begin{array}{c}\text { Precision } \\
(\%)\end{array}$ & RMSE_Test & RMSE_Train \\
\hline 60 & 87.5 & 100 & 66.7 & 0.33 & 0.31 \\
\hline 70 & 89.33 & 98.2 & 75.8 & 0.4082 & 0.3805 \\
\hline 80 & 93.4 & 95.4 & 83.2 & 0.25 & 0.17 \\
\hline
\end{tabular}

According to Fig. 10, clear decomposition between the phase-to-phase and phase-to-ground faults can be seen, confirming that the feature region for each fault is explicitly 
determined. There is a relatively small overlapping region between the two regions for fault feature.

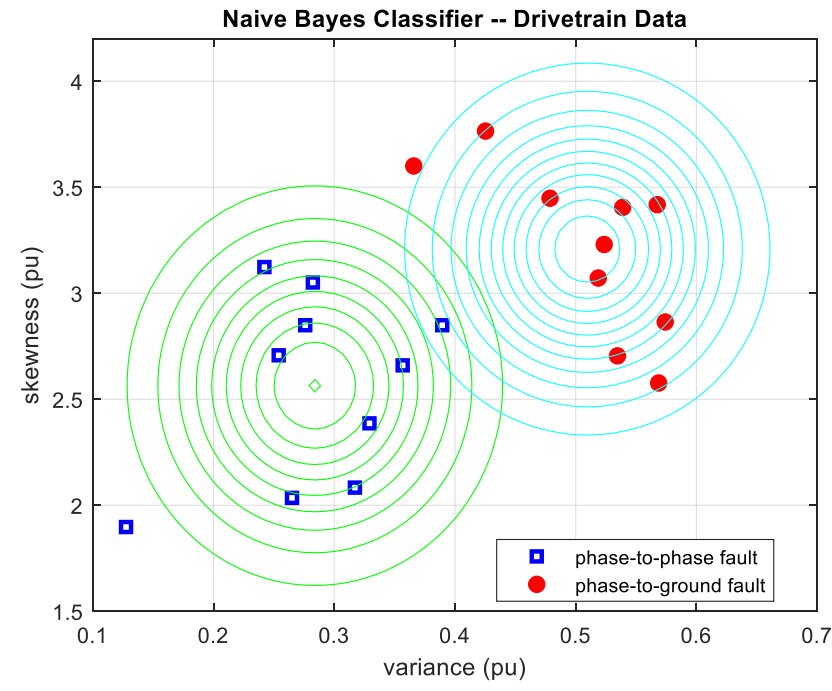

Fig. 10. The Gaussian contours of variance and skewness for the phase-tophase and phase-to-ground fault data using NBC classifier

\section{CONCLUSION}

In this paper, a hybrid procedure was proposed to detect and classify two electrical faults of the wind turbine generator namely single phase-to-phase fault and single phase-to-ground fault. Three-phase stator current signals were used as fault detection signals. Several features including skewness, variance, mean, D4 PSD variance, D4 variance, and Kurtosis were extracted using discrete wavelet transform and applied as the inputs to the naïve Bayes classifier model. At the fault detection stage, the best performance was achieved for $50 \%-50 \%$ prior probability. The performance of the classification was verified by exploring the contours of variance and skewness features. In addition, the NBC classifier was able to identify the types of faults with acceptable accuracy. The best accuracy of the classification stage was achieved when $80 \%$ of the data were considered as the train data. Furthermore, the contours of variance and skewness features using the NBC classifier showed that the algorithm is able to differentiate between the single phase-to-phase fault and single phase-to-ground fault. Future work will include considering a wider range of generator electrical faults, such as broken rotor bar and air gap eccentricity, in order to examine the practicality of the proposed hybrid fault detection model for wind turbine generators.

\section{REFERENCES}

[1] https://www.irena.org/wind

[2] https://www.ge.com/renewableenergy/wind-energy/offshore-wind

[3] W. Qiao, and L. Dingguo, "A survey on wind turbine condition monitoring and fault diagnosis-Part I: Components and subsystems," IEEE Trans. Indus. Elec, vol. 62, no. 10, pp. 6536-6545, 2015.

[4] T. Sellami, H. Berriri, M.F. Mimouni, S. Jelassi, and M. Darcherif, "Impact of inter-turn short-circuit fault on wind turbine driven squirrelcage induction generator systems," In Conférence Internationale en Sciences et Technologies Electriques au Maghreb CISTEM 2014.

[5] N.M. Freire, J.O. Estima, and A.J.M. Cardoso, "Open-circuit fault diagnosis in PMSG drives for wind turbine applications," IEEE Trans. Indust. elec, vol. 60, no. 9, pp. 3957-3967, 2012.

[6] N. Jin, J. Xing, Y. Liu, Z. Li, and X. Lin, “A novel single-phase-to-ground fault identification and isolation strategy in wind farm collector line," Int. J. Elect. Power Energy Syst, vol. 94, pp. 15-26, 2018.

[7] R. Strömbergsson, D., Marklund, P., Berglund, K., Saari, J., and A. Thomson, "Mother wavelet selection in the discrete wavelet transform for condition monitoring of wind turbine drivetrain bearings" Wind Energy, vol. 22, no.11, pp.1581-1592, 2019.

[8] S.J. Watson, B.J. Xiang, W. Yang, P.J. Tavner, and C.J. Crabtree, "Condition monitoring of the power output of wind turbine generators using wavelets," IEEE Trans. Energy Conv, vol. 25, no. 3, pp. 715-721, 2010.

[9] R. Roshanfekr, and A. Jalilian, "Wavelet-based index to discriminate between minor inter-turn short-circuit and resistive asymmetrical faults in stator windings of doubly fed induction generators: a simulation study," IET Gen. Trans. Distr, vol.10, vol. 2, pp. 374-381, 2016.

[10] J. Zhang, H. Sun, Z. Sun, W. Dong, and Y. Dong, "Fault diagnosis of wind turbine power converter considering wavelet transform, feature analysis, judgment and BP neural network," IEEE Access, vol. 7, pp. 179799-179809, 2019.

[11] M. Reder, and J.J. Melero, "A Bayesian approach for predicting wind turbine failures based on meteorological conditions," J. Phys. Conference Series, vol. 1037, no. 6, pp. 1-11, 2018.

[12] P. SangitaB, and S.R. Deshmukh, "Use of Support Vector Machine, decision tree and Naive Bayesian techniques for wind speed classification,” In 2011 International Conference on Power and Energy Systems, pp. 1-8. IEEE, 2011.

[13] S. Miller, "Wind Turbine Model," https://github.com/mathworks, 2012.

[14] M-F. Guo, X-D. Zeng, D-Y. Chen, and N-C. Yang, "Deep-learning-based earth fault detection using continuous wavelet transform and convolutional neural network in resonant grounding distribution systems," IEEE Sens. J, vol. 18, no. 3, pp. 1291-1300, 2017.

[15] M.J. Islam, Q.J. Wu, M. Ahmadi, and M.A. Sid-Ahmed, "Investigating the performance of naive-bayes classifiers and k-nearest neighbor classifiers," In 2007 International Conference on Convergence Information Technology (ICCIT 2007), pp. 1541-1546. IEEE, 2007.

[16] S. Theodoridis, A.K. Pikrakis, K. Koutroumbas, and D. Cavouras, Introduction to pattern recognition: a matlab approach. Academic Press, 2010 